American Journal of Environmental Sciences 7 (5): 409-414, 2011

ISSN 1553-345X

(C) 2011 Science Publications

\title{
Determination of Lead in Human Teeth by Hydride Generation Atomic Absorption Spectrometry
}

\author{
Hassan T. Abdulsahib \\ Department of Chemistry, College of Science, University of Basrah, Basrah, Iraq
}

\begin{abstract}
Problem statement: The determination of lead in human teeth at concentration levels of $\mu \mathrm{g} / \mathrm{ml}$ is proposed using Hydride Generation Atomic Absorption Spectrometry (HG-AAS). To do this, 2\% (w/v) lanthanum chloride solution was employed as matrix modifying reagent to increase sensitivity and remove matrix interferences. Approach: About $100 \mu \mathrm{L}$ of sample and $100 \mu \mathrm{L}$ of $3.0 \%(\mathrm{~m} / \mathrm{v}) \mathrm{NaBH}_{4}$ are simultaneously injected into carrier streams. The detection of limit of $0.46 \mu \mathrm{g} \mathrm{L} \mathrm{L}^{-1}$ for $\mathrm{Pb}$ was achieved and the relative standard deviation of $3.0 \%$ for $10 \mu \mathrm{g} \mathrm{L}^{-1}$ lead was obtained. The recovery percentage of the method had been found to be (92.8-100.5\%) for known quantities of lead added to teeth sample which were completely recovered. A comparison of the proposed method with standard addition method showed nearly results in the same samples of teeth and results compared with other studies in the world. Results: The method was shown to be satisfactory for determination of traces of lead in teeth samples with excellent accuracy. Teeth analysis reveals that intact teeth contained the highest amounts of lead which provide an evidence that lead may reduce the prevalence of dantal caries. Statistically significant differences $(\mathrm{p}<0.001)$ were observed between persons living in city centre and others who living in outskirt for concentrations of lead. Geographical influences are thought to be the main source of variability. No significant difference was shown for lead contents of teeth samples as a function of sex. Conclusion: Statistically significant difference between age groups are seen in the mean value of lead concentrations in human teeth, the concentration of lead increased with age. The differences may be due to the exposure of lead and others factors such as differences in diet and drinking water.
\end{abstract}

Key words: Lead, human teeth, hydride generation

\section{INTRODUCTION}

Tooth, a part of skeleton, is a bio-indicator of great interest because it contains information on exposure to essential or toxic elements that become deposited in the tooth material (Acar et al., 2008). Lead is the most interesting element, because of its physiological role in teeth, which may replace calcium in apatite and increasing resistance to caries (Ewers et al., 1996). This assumption has stimulated research into the determination of the distribution of lead in whole human teeth.

Methods which have been applied to the determination of Lead are atomic absorption (Larsen and Ludwigsen, 1997), Emission spectroscopy (Yoakum et al., 1975) and colorimetry are subject to series interferences. Hydride Generation combined with Atomic Absorption Spectrometric (HG-AAS) is a well developed technique can be used for the determination of volatile hydride-forming elements such as arsenic, selenium, antimony and others at trace levels (Dedina and Tsalev, 1995). The advantages of hydride generation atomic absorption spectrometry over other atomic absorption spectrometric techniques such as the flame and graphite furnace methods are increased atomization efficiency, higher selectivity because the analyte is removed from the matrix as a volatile compound and detection limits at the $\mu \mathrm{g} / \mathrm{L}$ level or lower for the elements cited above. Considering these advantages, it is providing that the potential this technique should be to applied for the lead and moreover, with this purpose it is possible to include this element in multi-element analysis schemes involving hydride generation.

Earlier spectrographic studies by Drea (1935) showed lead was consistently present in teeth. The mean lead content for deciduous teeth as given by Altshuller et al. (1962) was $15.1 \mathrm{ppm}$, Brudevold and Steadman (1956) found relatively high concentrations of lead in the external enamel layer which rapidly decreased towards the amelo-dental junction, in both erupted and unerupted teeth. The concentration of lead increased with age and the increased was more marked on the external than in the internal surface enamel, the concentration ranged $35-550 \mathrm{ppm}$.

Few figures are available for the concentrations of lead in dentine and dental plaque. Hardwick and Martin (1967) state that concentration in ashed dentine is between 1-10 and 10-100 ppm in ashed dental plaque. Putinam et al. (1966) give a mean concentration of 7.0 ppm for dental plaque and less than this $0.24-0.66 \mathrm{ppm}$ estimated for whole teeth. 
To the best of our knowledge there are no published data dealing with a matrix modified hydride generation atomic absorption spectrometry determination of microgram amounts of lead in whole human teeth. The described method is rapid, less expensive and requires no grinding of the teeth. No separation or preconcentration of lead is required. In addition the interference effects on lead signal was completely removed by matrix modifying reagent $\left(2 \% \mathrm{w} / \mathrm{v} \mathrm{LaCl}_{3} .7 \mathrm{H}_{2} \mathrm{O}\right)$.

\section{MATERIALS AND METHODS}

Instrumentation: For measurements, a Shimadzu atomic absorption spectrometer, model (AA-630-12, Japan) equipped with a hallow cathode lamp for lead was used. The determinations were carried out at $217 \mathrm{~nm}$, spectral band pass of $1.9 \mathrm{~nm}$ and lamp current of $10 \mathrm{~mA}$.

For atomization of lead, a T-shaped silica tube was used, which was cleaned weekly with acid. One of tubes was the atomization chamber $(170 \times 8 \mathrm{~mm}$ i.d.) and other serving as the inlet of gases. The atomization cell was mounted on the optical axis of the spectrometer. The temperature was obtained with an air-acetylene flame (Air 11.5 $\mathrm{L} \mathrm{min}^{-1}$, Acetylene 2.5 $\mathrm{L} \mathrm{min}^{-1}$ ).

The hydride generation system used has been described in detail elsewhere.

Reagents: All chemicals and reagents used were of analytical grade and de-ionized water was used for preparation solutions.

A lead standard solution (Aldrich) with a $\mathrm{Pb}$ concentration of $1000 \mathrm{mg} \mathrm{L}^{-1} \mathrm{~Pb}$ in $0.5 \mathrm{M} \mathrm{HCl}$ was diluted with de-ionized water to provide a working stock solution of $10.0 \mu \mathrm{g} \mathrm{mL}^{-1} \mathrm{~Pb}$. Working solutions were prepared daily by dilution of the $10.0 \mu \mathrm{g} \mathrm{mL}^{-1} \mathrm{~Pb}$ solution and must be used immediately.

A $3.0 \%(w / v) \mathrm{NaBH}_{4}$ (Fluka scientific company, $98 \%$ pure) solutions were prepared immediately before use by dissolving $3.0 \mathrm{~g}$ of the $\mathrm{NaBH}_{4}$ in $0.05 \mathrm{~mol} \mathrm{~L}^{-1}$ $\mathrm{KOH}$ (Aldrich).

An $2.0 \%(\mathrm{w} / \mathrm{v})$ lanthanum chloride (Aldrich) solution was prepared immediately before use by dissolving $2.0 \mathrm{~g}$ of the $\mathrm{LaCl}_{3} .7 \mathrm{H}_{2} \mathrm{O}$ in $100 \mathrm{~mL}$ of $0.5 \mathrm{M}$ $\mathrm{HCl}$ solution.

Preparation of samples: Intact, mottles and carious human teeth were collected from different area in Basrah city. The teeth were immediately placed in polyethylene vial and kept in $5^{\circ} \mathrm{C}$ to retard contamination. Before analysis, extraneous blood, tissues, bone and collagenous materials were removed from each tooth by agitation in $5 \mathrm{~mL}$ of $3 \%$ hydrogen peroxide for $5 \mathrm{~min}$. Next, the teeth were rinsed with distilled demineralized water and any remaining tissues were removed by scraping with a Teflon spatula. The samples were rinsed again in distilled demineralized water, air dried over night at $120 \pm 10^{\circ} \mathrm{C}$ in an air oven. Weigh the dried samples accurately into a Pyrex $50 \mathrm{~mL}$ conical flask, add $2 \mathrm{~mL}$ of concentrated nitric acid and $6 \mathrm{~mL}(60 \% \mathrm{w} / \mathrm{v})$ perchloric acid. Place a reflux condenser funnel in the flask and digest the mixture at $160 \pm 10^{\circ} \mathrm{C}$ with continuous stirring using mechanical stirrer until dense white fumes of perchloric acid and nitric acid evolved.Remove the reflux condenser funnel and evaporate the contents of the flask to incipient dryness. To the cooled flask add $10 \mathrm{~mL}$ of $2.0 \%$ (w/v) lanthanum chloride in $0.5 \mathrm{M} \mathrm{HCl}$ and replace the reflux funnel and boil the mixture for 5 minutes.Transfer the digest solution quantitatively to Pyrex glass tube calibrated to $25 \mathrm{~mL}$ and dilute it to the mark with lanthanum chloride.

\section{Procedure:}

A-The direct method: The calibration graph was prepared from different concentrations of the standard lead solutions corresponding to the appropriate lead concentration then diluted with deionized water instead of lanthanum.

B-Matrix modified standard additions method: Prepare standards containing $(2 \%$ w/v $) \mathrm{LaCl}_{3} .7 \mathrm{H}_{2} \mathrm{O}$ with $0,0.5,1.0,1.5$ and $2.0 \mathrm{ppm}$ of lead. Add $8 \mathrm{~mL}$ of each addition standard to different 2-mL aliquots of sample solution in $10 \mathrm{~mL}$ graduated flask to give "added" lead concentrations of $0,0.4,0.8,1.2$ and $1.6 \mathrm{ppm}$ of lead.

For both methods: A $100 \mu \mathrm{L}$ volume of the treated sample solution was placed in the reaction vessel and $100 \mu \mathrm{L}$ of $3 \% \mathrm{w} / \mathrm{v} \mathrm{NaBH}_{4}$ solution were added. The solution was mixed for $20 \mathrm{sec}$ and the formed lead hydride swept by nitrogen gas at a flow rate of $1.2 \mathrm{~L}$ $\mathrm{min}^{-1}$ into the heated atomization cell for determination by atomic absorption spectrometry.

Statistical analysis: The statistical analysis were carried out using two-way analysis of variance with unbalanced repeated measurements.Statistical significance between individual time points was made by using Revised Least Significant Difference (RLSD) test. The probability level for significance was $5 \%$ less.

\section{RESULTS AND DISSCUTION}

Interference effects: The effects of representative potential interference that are known to interfere in the hydride process at concentration levels possible in an aqueous solution of teeth were tested. 
Am. J. Environ. Sci., 7 (5): 409-414, 2011

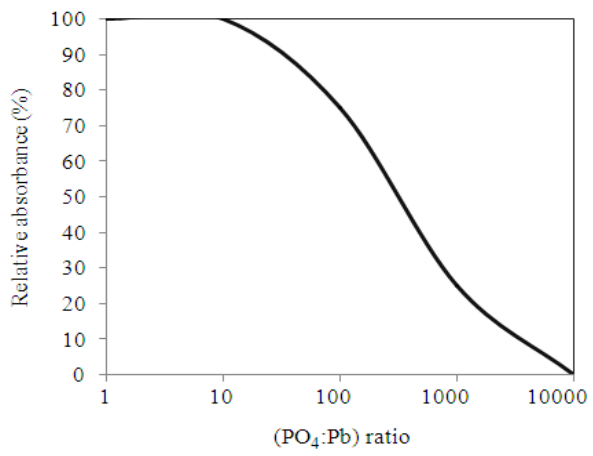

Fig. 1: Interferences effects of phosphate in $\mathrm{Pb}$ signal $\left(1 \mathrm{mg} \mathrm{L}^{-1}\right) \mathrm{Pb}$ solution

Table 1: Effect of (2\%w/v) lanthanum (III) on lead atomic absorption signal in human teeth samples

\begin{tabular}{lll}
\hline & Mean of absorbance & \\
\cline { 1 - 2 } Teeth samples no & With La (III) & Without La (III) \\
\hline 1 & 0.70 & 0.09 \\
2 & 0.62 & 0.10 \\
3 & 0.88 & 0.07 \\
4 & 0.79 & 0.17 \\
5 & 0.99 & 0.19 \\
\hline
\end{tabular}

$\mathrm{Sb}$ (III), As (III), Se (IV), Mn (II), Fe (III), Cu (II), $\mathrm{Ni}$ (II), Ca (II), $\mathrm{PO}_{4}$ (III) and $\mathrm{Al}$ (III) were evaluated in proposed method. To investigate the extent of their effects on the determination of lead, $1 \mathrm{mg} \mathrm{L}^{-1}$ of $\mathrm{Pb}$ (II) were spiked with levels of these potential interferents. Even when all the interferents were simultaneously present in the solution, these elements did not affect the signal, with exception of phosphate. $\mathrm{A} \mathrm{Pb}: \mathrm{PO}_{4}$ ratio of $1: 100$, corresponding to a total amount of phosphate of $200 \mathrm{mg} \mathrm{L} \mathrm{L}^{-1}$, produces a decrease of $25 \%$ in the analytical signal. At ratio 1:1000 the decrease is of order $75 \%$ Fig. 1. This interference takes place mainly in the gaseous phase and it is due to the volatile products of the reaction of the interferent with the sodiumtetrahydroborate. To eliminate the interferences of phosphate, lanthanum (III) has been used, Table 1 shows the effect of lanthanum on lead atomic absorption signal which was recorded for teeth samples with and without treatment with lanthanum, it has shown that the presence of $2 \%$ lanthanum(III) enhances the lead signal by factor of 3-10 times as compared with untreated samples solution. It is known that La (III) reacts with phosphate to form highly stable $\mathrm{LaPO}_{4}$ compounds which is probably stable enough to prevent the reaction of phosphate with sodiumtetrahydroborate and leaving lead free from interferences. According to Madrid et al. (1990), the magnitude of the effects were strongly dependent on the medium and atomization system used.

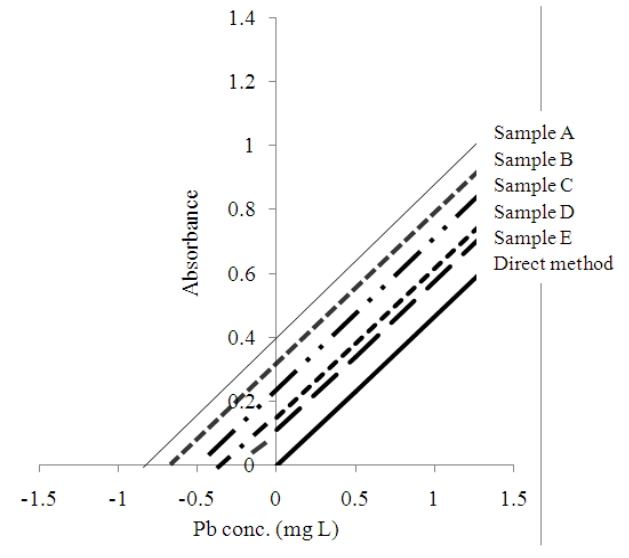

Fig. 2:Determination of $\mathrm{Pb}$ in human teeth by matrix modified: (1) Direct method (2) std. addition (A-E)

Table 2: Lead contents ( $\mu \mathrm{g} / \mathrm{gm}$, dry weight) of human teeth and relative standard deviation (7 replicates)

\begin{tabular}{|c|c|c|c|c|c|}
\hline \multirow[b]{2}{*}{ Samples } & \multirow{2}{*}{$\begin{array}{l}\text { Teeth dry } \\
\text { weight }(\mathrm{gm})\end{array}$} & \multicolumn{2}{|c|}{$\begin{array}{l}\text { Proposed method } \\
\mathrm{Pb} \text { content }\end{array}$} & \multicolumn{2}{|c|}{$\begin{array}{l}\text { Std. addition metho } \\
\mathrm{Pb} \text { content }\end{array}$} \\
\hline & & $\mu \mathrm{g} / \mathrm{gm}$ & RSD (\%) & $\mu \mathrm{g} / \mathrm{gm}$ & $\operatorname{RSD}(\%)$ \\
\hline A & 0.89 & 1.45 & 1.11 & 1.39 & 2.6 \\
\hline B & 0.93 & 1.07 & 2.40 & 0.99 & 1.9 \\
\hline $\mathrm{C}$ & 1.70 & 0.33 & 3.00 & 0.36 & 2.0 \\
\hline D & 1.34 & 0.52 & 1.32 & 0.59 & 1.2 \\
\hline E & 0.97 & 0.37 & 1.59 & 0.32 & 4.0 \\
\hline
\end{tabular}

Calibrations: The use of standard additions method without matrix modifier for lead analysis in human teeth gives non-reproducible and errornous results (RSD 10\%). In first step and to check the influence of a real matrix of teeth on the obtained results, two calibration curves were compared, the first was calibration curve constructed with standard solution of lead in $0.5 \mathrm{M} \mathrm{HCl}$ medium and the second was made by apply the matrix modified standard additions method to teeth samples whose content of lead. Table 2 demonstrate the obtained results for various types of teeth samples by matrix modified (a) direct method (b) standard additions method, by depending on the calibrations curves appears in Fig. 2 with good agreement between both results: $0.33-1.45 \mu \mathrm{g} \mathrm{g}^{-1}$ and $0.32-1.39 \mu \mathrm{g} \mathrm{g}^{-1}$ respectively. In both sets the absorbance measurement gives reproducible results with very low RSD\% (1.11-3\%) for direct method and $(1.2-4 \%)$ for standard additions method, which indicate excellent precision and reproducibility of the developed procedure and consequently its freedom from background and interelement effects. Since the slope of both calibration graphs are identical, either graph could be used for determination of lead using absorption mode of measurements. 
Am. J. Environ. Sci., 7 (5): 409-414, 2011

Table 3: Recovery percentage of the direct method of human teeth samples

\begin{tabular}{|c|c|c|c|c|}
\hline $\begin{array}{l}\text { Sample } \\
\text { no }\end{array}$ & $\begin{array}{c}\text { Pb content } \\
(\mu \mathrm{g} / \mathrm{mL})\end{array}$ & $\begin{array}{l}\text { Pb added } \\
(\mu \mathrm{g})\end{array}$ & $\begin{array}{l}\text { Pb found } \\
(\mu \mathrm{g})\end{array}$ & Recovery (\%) \\
\hline$\overline{1}$ & 0.72 & 0.5 & 1.19 & 97.5 \\
\hline 2 & 0.34 & 0.5 & 0.78 & 92.8 \\
\hline 3 & 0.55 & 1.0 & 1.53 & 98.9 \\
\hline 4 & 1.02 & 1.0 & 2.02 & 100.0 \\
\hline 5 & 0.45 & 1.5 & 1.96 & 100.5 \\
\hline 6 & 0.93 & 1.5 & 2.42 & 99.5 \\
\hline
\end{tabular}

Sensitivity, detection limit and precision: The sensitivity of proposed direct method (1\% absorption) achieved in teeth sample was $1.97 \mu \mathrm{g} \mathrm{L}^{-1}$.

The absolute detection limit (3s) was $0.46 \mu \mathrm{g} \mathrm{L}^{-1}$, calculated for injected aliquots of a solution of $10 \mu \mathrm{g}$ $\mathrm{L}^{-1}$ lead in $\mathrm{HCl}$ media. This correspond to a $1 \mathrm{~mL}$ addition of sample. The precision of the direct method was determined from results of seven replicates of typical teeth sample, Relative Standard Deviation (RSD $\%$ ) was found to be $1.11-3.0 \%$.

Recovery studies: To check the accuracy of the method, known quantities of lead added to teeth samples and taken through the entire procedure and the recoveries were between $92.8-100.5 \%$, as appears from Table 3 were calculated with three replicates analyze of spiked teeth at the three indicated levels. The accuracy of the proposed direct method depend on the matrix effects which is negligible for samples prepared in accordance with the recommended weight-to-volume ratio. Thereby the direct method being an accurate produce for analysis of lead in human teeth.

Variations of lead contents in teeth: The lead contents was determined in the human teeth samples, collected from persons living in different areas of Basra city. The obtained results are shown in Table 4 together with the literature data (Altshuller et al., 1962; Brudevold and Steadman, 1956; Hardwick and Martin, 1967; Bachanek et al., 2000) which was obtained by using a different analytical method. Figure 3 illustrates the variation in the concentration of lead in human teeth as a function of life environments. Statistically significant differences $(p<0.001)$ were observed between persons living in city centre and others who living in outskirt for concentrations of lead. Geographical influences are thought to be the main source of variability. The observed variations are probably a reflection of the varying levels present in foods, that are generally dependent on geochemical environment in which they are living. Environmental contamination can also be a source of lead a human teeth.

For lead contents of teeth samples as a function of sex Fig. 4, however, no significant difference was shown $(\mathrm{p}<0.05)$. The means $(x \pm$ s.d) were $(0.763 \pm 0.132) \mu \mathrm{g} / \mathrm{g}$ and $(0.717 \pm 0.244) \mu \mathrm{g} / \mathrm{g}$ for men and women respectively.
Table 4: Lead contents ( $\mu \mathrm{g} / \mathrm{gm}$, dry weight) of human teeth in comparison with other studies

\begin{tabular}{lll}
\hline $\begin{array}{l}\text { Pb content } \\
(\mathrm{ppm})\end{array}$ & Method & Reference \\
\hline $29-550$ & Spectrophotometry & Brudevold and Steadman (1956) \\
15.1 & Spectrophotometry & Altshuller et al. $(1962)$ \\
$1-10$ & Mass spectrometry & Hardwick and Martin (1967) \\
7.0 & X-ray spectroscopy & Putinam et al. (1966) \\
1.78 & Electrothermal AAS & Bachanek et al. $(2000)$ \\
$0.24-0.66$ & Electrothermal AAS & Awad \\
$0.33-1.45$ & HGAAS & Present study \\
\hline
\end{tabular}

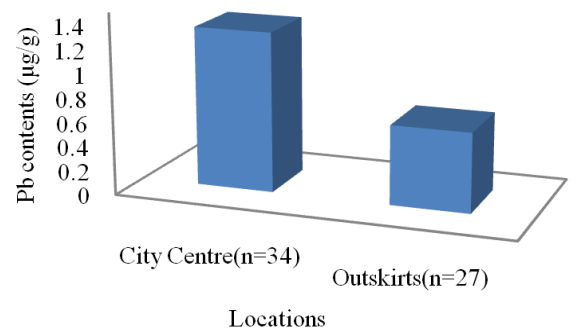

Fig. 3: $\mathrm{Pb}$ Contents $(\mu \mathrm{g} / \mathrm{g}$, dry wt.) of human teeth as a function of locations

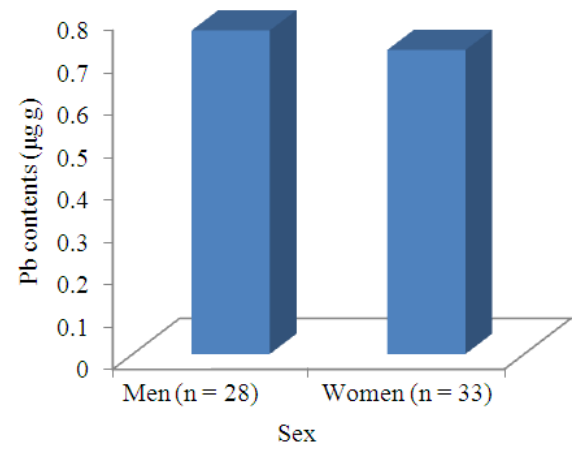

Fig. 4: Pb Contents ( $\mu \mathrm{g} / \mathrm{g}$, dry wt.) of human teeth as a function of sex.

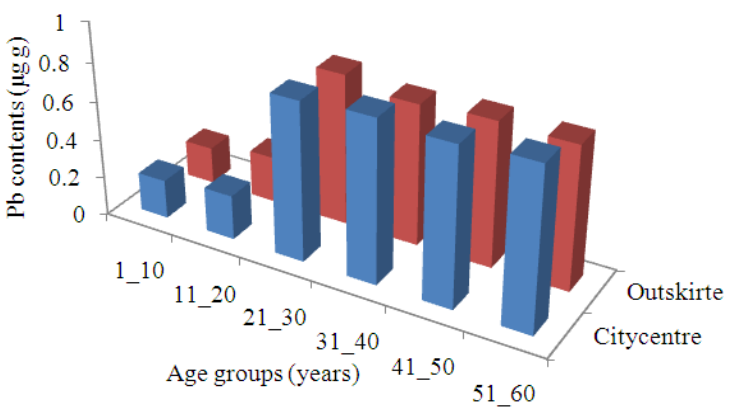

Fig. 5: $\mathrm{Pb}$ contents $(\mu \mathrm{g} / \mathrm{g}$, dry wt.) of human teeth as a function of age groups

This data indicates that there was no influence from the sexes of groups on lead contents of teeth. 


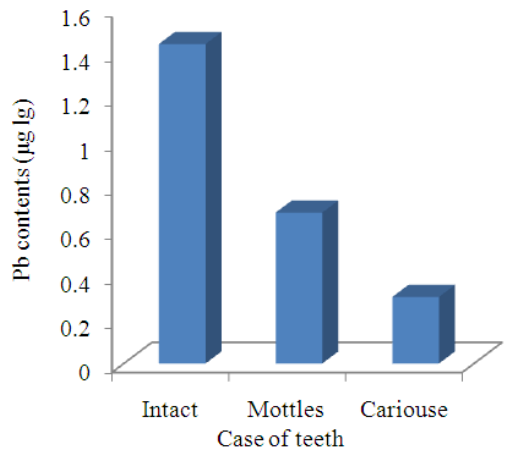

Fig. 6: $\mathrm{Pb}$ contents $(\mu \mathrm{g} / \mathrm{g}$, dry wt.) of human teeth as a function of teeth case

Statistically significant difference between age groups were seen in the mean value of lead concentrations in human teeth $(\mathrm{p}<0.01)$ as shown in Fig. 5. The concentration of lead increased with age and this concentration remained nearly constant from (21-30 years) to (51-60 years) age group of persons. The differences may be due to the exposure of lead and others factors such as differences in diet and drinking water.

On the other hand, it is found out that there is a statistical relationship between the lead contents in teeth as a function of the teeth cases $(\mathrm{p}<0.01)$. Since the concentrations of lead are found to be $\left(1.44 \pm 0.29 \mu \mathrm{g} \mathrm{g}^{-1}\right)$ in the intact teeth, $\left(0.68 \pm 0.16 \mu \mathrm{g} \mathrm{g}^{-1}\right)$ in the mottles teeth and $\left(0.30 \pm 0.09 \mu \mathrm{g} \mathrm{g}^{-1}\right)$ in the caries teeth Fig. 6. These results ascribed to the role of lead in teeth, lead replace calcium in teeth and reduce the prevalence of dental caries.

\section{CONCLUSION}

The use of lanthanum (III) as matrix modifier has proven to constitute an effective approach for the determination of lead by hydride generation technique. The proposed method provides adequate sensitivity, selectivity and accuracy for the direct determination of lead in teeth samples without pre-concentration and complexing agents procedures. The principal advantages of the proposed method including the possibility of micro-sampling analysis, increased sample throughput (120 samples per hour). $\mathrm{NaBH}_{4}$ consumption is about $12 \mathrm{~mL}$ and waste generation in the order of $250 \mathrm{~mL} \mathrm{~h}^{-1}$, thus making this method an environmentally friendly. Thus due all these advantages making this method an attractive technique for routine determination of trace amounts of lead in matrices such as phosphate rocks, biological materials and bones, where high contents of phosphate are present. For teeth samples, the described method is equivalent to the method of standard additions, therefore,these was used in the study of the role of lead in teeth. The high levels of lead in the intact teeth provide evidence that lead increase resistance to caries. Also the differences in diet and drinking water And the exposure to lead led to the vareity in the lead levels as a function of age and environmental life.

\section{ACKNOWLEDEMENT}

The researcher thankful for the assistance of A. Alhaidary for field sampling. The helpful comments on the manuscript by N, A. Awad and M.T.Jabbar are gratefully acknowledged.

\section{REFERENCES}

Acar, O., A.R. Turker and Z. Kilic, 2008. Flame atomic absorption spectrometric determination of iron, magnesium, strontium and zinc in human teeth using $\mathrm{La}+\mathrm{K}$ mixture. Acta Chim. Slov., 55: 462467.

Altshuller, L.E., D.B. Halak, B.H. Landing and R.A. Vehoe, 1962. Deciduous teeth as an index of body burden of lead. J. Pediat., 60: 224-229. DOI: 10.1016/S0022-3476(62)80040-7

Bachanek, T., E. Staroslawska, E. Wolanska and K. Jarmolinska, 2000. Heavy metal poisoning in glass worker characterised by severe. Ann. Agric. Environ. Med., 7: 51-53. PMID: 10865245

Brudevold, F. and L.T. Steadman, 1956. The distribution of lead in human enamel. J. Dent. Res., 35: 430-437. DOI: 10.1177/00220345560350031401 PMID: 13332147

Dedina, J. and D.L. Tsalev, 1995. Hydride Generation Atomic Absorption Spectrometry. 1st Edn., Wiley, Chichester, ISBN-10: 0471953644, pp: 526.

Drea, W.F., 1935. Spectrum analysis of dental tissues for "trace" elements. J. Dent. Res., 15: 403-406. DOI: $10.1177 / 00220345350150060401$

Ewers, U., M. Turfeld, I. Freier, I. Hofstetter and G. Stemmann et al., 1996. Lead and cadmium content in deciduous teeth of children of Stolberg and other cities of North-Rhine-Westphalia: A chronological trend 1968-1993. Zentralbl Hyg. Umweltmed, 198: 318-330. PMID: 9376057

Hardwick, J.L. and C.J. Martin, 1967. A pilot study using mass spectrometry for the estimation of the trace element content of dental tissues. Helv. Odont. Acta, 11: 62-70. PMID: 6022587 
Larsen, E.H. and M.B. Ludwigsen, 1997. Determination of iodine in food-related certified reference materials using wet ashing and detection by inductively coupled plasma mass spectrometry J. Anal. At. Spectrom., 12: 459-464. DOI: 10.1039/a607430h

Madrid, Y., M. Bonilla and C. Camara, 1990. Evaluation of oxidant media for the determination of lead in food slurries by hydride generation atomic absorption spectrometry. Analyst, 115: 563-565. PMID: 2396745
Putinam, N.A., F. Bradshaw and P. Platt, 1966. X-ray spectroscopic determination of the constituent elements of dental plaque. Adv. Fluorine Res., 4: 157-162. PMID: 5220577

Yoakum, A.M., P.L. Stewart and J.E. Sterrett, 1975. Method development and subsequent survey analysis of biological tissues for platinum, lead and manganese content. Environ. Health Perspect., 10: 58-93. 